\title{
Oxidative stress and outcome of antioxidant supplementation in patients with polycystic ovarian syndrome (PCOS)
}

\author{
Abubakar A. Panti ${ }^{1 *}$, Constance E. Shehu' ${ }^{1}$, Yusuf Saidu² ${ }^{2}$ Karima A. Tunau ${ }^{1}$, \\ Emmanuel I. Nwobodo', Abdulgafar Jimoh ${ }^{3}$, Lawal S. Bilbis ${ }^{2}$, \\ Atteque B. Umar' ${ }^{2}$, Mairo Hassan ${ }^{1}$
}

\begin{abstract}
${ }^{1}$ Department of Obstetrics and Gynaecology, ${ }^{2}$ Department of Biochemistry, ${ }^{3}$ Department of Pharmacology, Usmanu Danfodiyo University Sokoto, Nigeria
\end{abstract}

Received: 05 February 2018

Accepted: 07 March 2018

\section{* Correspondence:}

Dr. Abubakar A. Panti,

E-mail: kapanti2002@gmail.com

Copyright: (C) the author(s), publisher and licensee Medip Academy. This is an open-access article distributed under the terms of the Creative Commons Attribution Non-Commercial License, which permits unrestricted non-commercial use, distribution, and reproduction in any medium, provided the original work is properly cited.

\section{ABSTRACT}

Background: PCOS is a condition with significant decrease in antioxidant with an increased risk of oxidative stress. Antioxidant supplementation has been shown to improve insulin sensitivity in PCOS and may improve outcome of management of PCOS. Objectives of this study were to determine the oxidative stress level of PCOS patients, to assess the effect of antioxidant supplementation on the outcome of management of PCOS and to compare with a control group.

Methods: The study was a single blind randomised control trial involving 200 patients with PCOS. The study was conducted at Usmanu Danfodiyo University Teaching Hospital Sokoto. They were randomly divided into intervention and control groups and base line serum levels of oxidative stress marker, antioxidant enzymes, vitamins and minerals were determined. Antioxidant supplementation and placebo were given to the intervention and control groups respectively. All the patients had ovulation induction with clomiphene citrate and were followed up for 6 months. Outcome measures were clinical pregnancy or menstrual regularisation. Level of significance was <0.05.

Results: There was statistical significance in the serum levels of oxidative stress marker, antioxidant enzymes, vitamins and minerals between the two groups (post intervention). Glutathione peroxidase $(\mathrm{p}=0.001)$, superoxide dismutase $(\mathrm{p}=0.0001)$, catalase $(\mathrm{p}=0.0369)$, melondialdehyde $(\mathrm{p}=0.007)$, Vitamin A, Vitamin $\mathrm{C}, \mathrm{Vitamin} \mathrm{E}(\mathrm{p}=$ $0.0001)$, zinc and copper $(\mathrm{p}=0.0001)$. The clinical pregnancy outcomes were $22(22 \%)$ versus $2(2 \%)$; live births 18 $(18 \%)$ versus $2(2 \%)$ and menstrual regularisation $48(48 \%)$ versus $46(46 \%)$ in the intervention and control groups respectively.

Conclusions: Antioxidant supplementation in this study significantly affected pregnancy rate in patients with PCOS. Larger studies are suggested to revisit the conclusion of the Cochrane review that antioxidants supplementation had no significant role in female infertility.

Keywords: Antioxidants, Nigeria, Oxidative stress, PCOS, Supplementation

\section{INTRODUCTION}

Polycystic ovarian syndrome (PCOS) is one of the most common endocrinopathies affecting women of child bearing age and a major cause of anovulatory infertility. ${ }^{1}$
It is also associated with cardiovascular risk factors including obesity, insulin resistance, dyslipidemia, endothelial dysfunction and presence of metabolic syndrome. ${ }^{2}$ PCOS has been regarded as a chronic systemic disease instead of the simple local disease, and 
it is frequently associated with hyperandrogenaemia, chronic inflammation and oxidative stress. ${ }^{3}$

The mechanism underlying oxidative stress in PCOS is not fully understood, but studies strongly suggest that insulin resistance plays a pivotal role in the pathogenesis of PCOS and encourages oxidative stress. ${ }^{4}$ Oxidative stress (OS) is caused by imbalance between pro- oxidant and antioxidants. ${ }^{5}$ This ratio can be altered by increased levels of reactive oxygen species (ROS) and /or reactive nitrogen species (RNS), or decrease in antioxidant defence mechanism. ${ }^{6}$ Reactive oxygen species are produced mainly by the mitochondria and must be constantly inactivated to avoid excess formation in order to maintain normal cell function. ${ }^{7}$ The ovaries, testes, and uterus are particularly affected by ROS because they contain the highest amount of mitochondria in the body due to the need for ATP or energy in those processes. ${ }^{8}$ OS plays a critical role in the process of ovulation by inducing apoptosis of luteal cells within the ovary which perturbs the area in and around the ova and granulosa cells that potentially decrease oocyte and embryo viability. ${ }^{9}$ The imbalance of $\mathrm{OS}$ in the follicular fluid environment of the ovaries can cause detrimental issues, such as poor oocyte development, embryo development and the overall outcome of pregnancy. ${ }^{9}$

Antioxidant enzymes such as catalase, superoxide dismutase (SOD) and glutathione peroxidase (GPX) may inactivate ROS and help protect oocyte and embryo. ${ }^{7}$ Oxidative stress can form through increased production of ROS or due to deficiency of antioxidants. ${ }^{7}$ Antioxidants quench free radicals by becoming reduced. ${ }^{10}$ A deficiency of antioxidants could be due to decrease antioxidant intake, synthesis of antioxidant enzymes, or increase antioxidant utilization. ${ }^{11}$

There are two categories of antioxidants; primary/enzymatic/natural and secondary/non-enzymatic/ synthetic. Enzymatic antioxidants include; SOD, catalase and GPX. The non-enzymatic antioxidants include vitamin $\mathrm{E}$, vitamin $\mathrm{C}$, beta carotene, lutein, $\alpha$ - lipoic acid, selenium, lycopene, taurine, L- carnitine, co enzyme Q 10 etc. ${ }^{11}$ There are three SOD isoforms in eukaryotes; manganese SOD (Mn- SOD), copper/zinc SOD (cu/zn SOD) and extracellular SOD (EC-SOD). Antioxidants can be generated endogenously (enzymatic) or received from foods or supplements (non- enzymatic). ${ }^{10}$

PCO is a condition with significant decrease in serum antioxidant and vitamins levels and they are in an increased risk of oxidative status. ${ }^{12}$ Antioxidant supplementations has been shown to improve insulin sensitivity and other health threatening conditions in women with PCOS. ${ }^{12}$ There is paucity of data on oxidative stress and antioxidant supplementation in patients with PCOS especially in Africa. The aim of this study was to determine the oxidative stress level of PCOS patients and to assess the effect of antioxidant supplementation on the outcome of management of infertility in these group of women.

\section{METHODS}

This study was a single blinded randomised controlled trial involving 200 patients with PCOS who presented to the Gynaecological Clinic at the Department of Obstetrics and Gynaecology, Usmanu Danfodiyo University Teaching Hospital (UDUTH), Sokoto, Nigeria.

The study was carried out between January 2014 and August 2017. The diagnosis of PCOS was based on the Rotterdam criteria with women satisfying at least two out of three of the following criteria: ${ }^{13}$

- Oligomenorrhoea /or amenorrhoea

- Clinical /or biochemical sign of hyperandrogenism

- Polycystic ovaries on ultrasonography.

The ultrasound criteria for polycystic ovaries was defined as the presence of 12 or more follicles measuring 2 to 9 $\mathrm{mm}$ in diameter and or an increased ovarian volume greater than $10 \mathrm{~cm}^{3}$ on transvaginal ultrasound scanning.

\section{Inclusion criteria}

Patients that presented with anovulatory infertility due to PCOS.

\section{Exclusion criteria}

- Male factor infertility

- Tubal factor infertility (abnormal hysterosalpingography)

- Abnormal serum prolactin level

- Hypertension, kidney, liver or thyroid disease patients

- Smokers

- Alcoholic beverage use

- Use of medications like anti diabetic, anti-obesity drugs, insulin or vitamin and mineral supplements.

The trial was approved by UDUTH Ethics Committee and informed consent was obtained from participants. The women were randomised into two groups by picking one of two closed envelops. Within each envelop was a paper inscription of odd or even number.

The odd numbers were for intervention group while the even numbers were for the control group. The selection of add or even number were for intervention or control group was done by toss of coin. The two groups were concealed after randomisation by writing the allotted even or odd number on top of the trial sticker on the patient's folder. Only the researchers know who was for which group. 
Two hundred patients with PCOS were recruited. One hundred patients were given placebo (a capsule containing ferrous fumerate $100 \mathrm{mg}$ ) while the other hundred were given an intervention of a drug called (Vitacap $^{\mathrm{R}}$ ) which contains vitamin A (Palmitate) $5000 \mathrm{iu}$, vitamin B1 (Thiamine mononitrate) $5 \mathrm{mg}$, vitamin B6 (pyridoxine HCL) $2 \mathrm{mg}$, vitamin B12 (cyanocobalamin) 5 $\mathrm{mg}$, Vitamin C $75 \mathrm{mg}$, Vitamin D3 (cholecalciferol) 400 iu, Vitamin E (d- alpha tecopheryl acetate) $15 \mathrm{mg}$, Nicotinamide $45 \mathrm{mg}$, folic acid $1000 \mathrm{mcg}$, ferrous fumerate $50 \mathrm{mg}$, dibasic calcium phosphate $70 \mathrm{mg}$, Copper sulphate $0.1 \mathrm{mg}$, Manganese sulphate $0.01 \mathrm{mg}$, Zinc sulphate $50 \mathrm{mg}$, Potassium iodide $0.025 \mathrm{mg}$ and Magnesium oxide $0.5 \mathrm{mg}$.

Both drugs were administered to both groups for six months respectively which ended in April 2015 (period of intervention). All the patients had ovulation induction with clomiphene citrate $100 \mathrm{mg}$ for five days started on the second day of the menstrual cycle for up to six months. The outcome measures were clinical pregnancy or regularisation of menses. Those that achieved pregnancies were followed up till the last delivery in January 2016. The contact address and phone numbers of the couples were obtained which resulted in few drop outs, 2 from the intervention group and 3 from the control group. The five drop-outs relocated to other states within the country but still maintained phone contact all through the follow up period. The babies were followed up for 18 months for any neurological problem till August 2017.

\section{Chemicals and reagents}

Analytical graded chemicals and reagents were used for this research. Glutathione peroxidase kit (item number: 703102), superoxide dismutase kit (item number: 706002), TBARS assay kit (item number: 10009055) and catalase assay kit (item number: 707002) were all products of Cayman Chemical Company, USA. Vitamin $\mathrm{A}, \mathrm{C}$ and $\mathrm{E}$ were all product of Lab Tech Chemicals, India. DNPH reagent, thiourea, were all products from Sigma Company, United States of America.

\section{Equipment}

Micropipette reader RT 2100 C Rayfo Life and Analytical Science Company Limited, China was used to take absorbance of analysis involving kits. Analysis of minerals was carried out using Atomic absorption spectrophotometer (AAS) AA240FS AAS (Varian Medical Systems Inc. USA) while vitamin analysis was carried out using Spectrophotometer (Optima sp-300), United States of America.

\section{Collection of serum samples}

Under aseptic precautions $7 \mathrm{ml}$ of blood was drawn in plain vacutainer tubes from antecubital veins of the subjects in the fasting state on day 2 of their menstrual cycle. The collected blood was allowed to clot and then centrifuged at $4000 \mathrm{rpm}$ for 10 minutes to clear separation of serum. Serum thus extracted was divided into three aliquot samples stored at $-20^{\circ} \mathrm{C}$ for analysis of: Glutathione peroxidase, Super oxide dismutase (SOD), Catalase, Malondialdehyde, Vitamin (A, C and E) and Minerals (Copper and Zinc). The blood collection for analysis was done twice first pre- intervention and six months later (post-intervention).

\section{Determination of antioxidant status}

Serum glutathione peroxidase (GPX) activity was determined according to the method described by Paglia and Valentine, using hydroperoxide as substrate. ${ }^{14}$

The serum SOD enzymatic activity was determined according to the method reported by Marklund. ${ }^{15}$ Serum MDA levels was determined by the method of Niehans and Samuel. ${ }^{16}$ Lipid peroxidation was evidenced by formation of thiobarbituric acid (TBA). Serum catalase activity was determined using Cayman's catalase assay kit according to Johansson and Borg. ${ }^{17}$ Serum vitamin E was assayed using the method of Hashim and Schuttrnger. ${ }^{18}$ Ascobic acid (Vitamin C) was assayed by the method of Natelson. ${ }^{19}$ Vitamin A was determined by the method of Rutkowski et al. ${ }^{20}$

Atomic absorption Spectrophotometer (AAS) model AA240FS AAS (Varian Medical systems Inc. USA) was used in the determination of $\mathrm{Zn}$ and $\mathrm{Cu}$ by the method of Fick et al. ${ }^{21}$

\section{Statistical analysis}

Results were expressed as mean \pm SEM by using Instat Software (version 3.0) San Diego, USA. The Data was subjected to analysis of variance (ANOVA) and Turkey's t-test was used for comparison of means between two groups. The statistical significance level was set at $\mathrm{P}$ $<0.05$.

\section{RESULTS}

All the subjects were within the reproductive age group (18-35years). The mean ages of the intervention and control subjects were $28.18 \pm 0.82$ and $28.12 \pm 0.81$ (values \pm SEM) respectively.

Majority of the subject's educational level is above secondary level $74 \%$ and $76 \%$ in the intervention and control subjects respectively which make it easier for the subjects to comprehend and accurately carry out the instructions given. The anthropometric index showed that the average BMI of the intervention and control subjects was $27.9 \pm 0.85$ and $29.47 \pm 0.82$ (values \pm SEM) respectively.

It was observed from this study that secondary infertility had more number of subjects, $66 \%$ as compared to $34 \%$ of primary infertility in both groups. 
Table 1: Clinical presentation of the subjects.

\begin{tabular}{|llll|}
\hline General & Intervention & Control & \\
$\mathbf{N}(\%)$ & $\mathbf{N}(\mathbf{1 0 0})$ & $\mathbf{N}(\mathbf{1 0 0})$ & \\
\hline Oligomenorrhoea & $192(96)$ & 94 & 98 \\
\hline Amenorrhoea & $158(79)$ & 74 & 84 \\
\hline Hirsutism & $40(20)$ & 18 & 22 \\
\hline Acne & $50(25)$ & 24 & 26 \\
\hline PCOS & $200(100)$ & 100 & 100 \\
\hline
\end{tabular}

Majority of the patients presented with oligomenorrhoea and amenorrhoea comparatively in both study groups. The clinical features of hyperandrogenism were few in both study groups however; one hundred percent of patients had diagnostic ultrasound morphology by Tran's vaginal ultrasound (Table 1).

Table 2: Pre-intervention antioxidant enzymes, vitamins and minerals in subjects.

\begin{tabular}{|llll|}
\hline & $\begin{array}{l}\text { Intervention } \\
(\mathrm{n}=100)\end{array}$ & $\begin{array}{l}\text { Control } \\
(\mathrm{n}=100)\end{array}$ & $\begin{array}{l}\text { P- } \\
\text { value }\end{array}$ \\
\hline $\begin{array}{l}\mathrm{GPx} \\
(\mathrm{nmol} / \mathrm{min} / \mathrm{ml})\end{array}$ & $15.52 \pm 0.54$ & $15.27 \pm 0.42$ & 0.4345 \\
\hline $\mathrm{SOD}(\mathrm{units} / \mathrm{ug})$ & $1.18 \pm 0.05$ & $1.19 \pm 0.07$ & 0.4888 \\
\hline $\begin{array}{l}\mathrm{CAT} \\
(\mathrm{nmol} / \mathrm{min} / \mathrm{ml})\end{array}$ & $38.51 \pm 1.59$ & $38.85 \pm 1.63$ & 0.1207 \\
\hline $\mathrm{MDA}(\mu / \mathrm{ml})$ & $3.91 \pm 0.05$ & $3.99 \pm 0.05$ & 0.1207 \\
\hline $\mathrm{Cu}(\mu \mathrm{g} / \mathrm{L})$ & $48.67 \pm 3.32$ & $47.27 \pm 5.45$ & 0.3782 \\
\hline $\mathrm{Zn}(\mu \mathrm{g} / \mathrm{L})$ & $30.05 \pm 0.88$ & $30.26 \pm 0.97$ & 0.4112 \\
\hline $\mathrm{Vit} \mathrm{A}(\mathrm{mg} / \mathrm{dl})$ & $7.26 \pm 0.33$ & $6.96 \pm 0.29$ & 0.1691 \\
\hline Vit C $(\mathrm{mg} / \mathrm{dl})$ & $0.33 \pm 0.04$ & $0.34 \pm 0.05$ & 0.3529 \\
\hline Vit E $(\mathrm{mg} / \mathrm{dl})$ & $2.59 \pm 0.03$ & $2.57 \pm 0.03$ & 0.378 \\
\hline
\end{tabular}

Values are expressed as mean \pm SEM, GPx-glutathione peroxidase, SOD: superoxide dismutase, CAT: catalase, $\mathrm{Cu}$ : copper, Zn: zinc, Vit: vitamin.

The pre-intervention means oxidative stress marker and antioxidants enzymes, vitamins and minerals are not statistically significant between the two groups (Table 2).

There was a statistically significant difference in the serum levels of the mean oxidative stress marker, antioxidant enzymes, vitamins and minerals between the intervention and the control group (Table 3).

Twenty-two pregnancies were recorded in the intervention group (22\%) while only 2 in the control group (2\%). All the 2 pregnancies in the control group ended in live birth while 18 out of 22 in the intervention group had live births (Table 4).

Four out of the 22 pregnancies achieved had miscarriages 3 were first trimester miscarriages ranging from 6 to 8 weeks while one was at 18 weeks following failed emergency cerclarge application due to cervical incompetence. Out of the remaining patients that did not achieve pregnancy $48 \%$ and $46 \%$ observed that their menses had become regular in intervention and control group respectively (Table 4).
Table 3: Post-intervention antioxidant enzymes, vitamins and minerals in subjects.

\begin{tabular}{|llll|} 
& $\begin{array}{l}\text { Intervention } \\
(\mathrm{n}=100)\end{array}$ & $\begin{array}{l}\text { Control } \\
(\mathrm{n}=100)\end{array}$ & $\begin{array}{l}\text { P } \\
\text { value }\end{array}$ \\
\hline $\begin{array}{l}\mathrm{GPx} \\
(\mathrm{nmol} / \mathrm{min} / \mathrm{ml})\end{array}$ & $22.36 \pm 0.37^{*}$ & $15.99 \pm 0.11$ & $<0.001$ \\
\hline $\mathrm{SOD}(\mathrm{units} / \mathrm{ug})$ & $2.00 \pm 0.03^{*}$ & $1.22 \pm 0.02$ & $<0.0001$ \\
\hline $\begin{array}{l}\mathrm{CAT} \\
(\mathrm{nmol} / \mathrm{min} / \mathrm{ml})\end{array}$ & $44.72 \pm 1.66^{*}$ & $38.36 \pm 1.97$ & $<0.0369$ \\
\hline $\mathrm{MDA}(\mu / \mathrm{ml})$ & $2.89 \pm 0.06^{*}$ & $3.75 \pm 1.61$ & $<0.007$ \\
\hline $\mathrm{Cu}(\mu \mathrm{g} / \mathrm{L})$ & $103.30 \pm 3.85^{*}$ & $48.09 \pm 167$ & $<0.0001$ \\
\hline $\mathrm{Zn}(\mu \mathrm{g} / \mathrm{L})$ & $60.44 \pm 3.09^{*}$ & $30.24 \pm 0.89$ & $<0.0001$ \\
\hline Vit A $(\mathrm{mg} / \mathrm{dl})$ & $50.97 \pm 0.35^{*}$ & $7.25 \pm 0.35$ & $<0.0001$ \\
\hline Vit C $(\mathrm{mg} / \mathrm{dl})$ & $1.77 \pm 0.02^{*}$ & $0.37 \pm 0.02$ & $<0.0001$ \\
\hline Vit E $(\mathrm{mg} / \mathrm{dl})$ & $8.81 \pm 0.07^{*}$ & $2.56 \pm 0.02$ & $<0.0001$ \\
\hline
\end{tabular}

*values differ from the non-intervention significantly at $\mathrm{P}<0.05$; Values are expressed as mean \pm SEM; GPx: glutathione peroxidase; SOD: superoxide dismutase; CAT: catalase; $\mathrm{Cu}$ : copper; Zn: zinc; Vit: vitamin

In the patients with primary infertility, 8 achieved pregnancy and all are in the intervened group while in secondary infertility 16 achieved pregnancy with 4 coming from the control group. All the babies had normal developmental milestone with no neurological developmental abnormality. One baby from the intervention group died of severe malaria at 1 year 2 months.

\section{DISCUSSION}

Polycystic ovary syndrome is a major cause of anovulatory infertility. ${ }^{22}$ Oxidative stress can have detrimental effects on female fertility by affecting ovulation, fertilization, embryo development and implantation. ${ }^{23}$ Studies have shown high oxidative stress in PCOS women compared to control. ${ }^{12,24,25}$ PCOS produce significant reduction in serum antioxidant Vitamins A, C and E when compared to control. ${ }^{12}$ Antioxidant supplementation has been shown to improve insulin sensitivity and other health threatening conditions in women with PCOS. ${ }^{12}$ The present study assessed the role of antioxidants supplementation in patients with PCOS using three natural antioxidants, three vitamins, two minerals and MDA as oxidative stress marker both pre-intervention and post-intervention and compared the outcome measures as in the methodology in the two groups. The mean age of the study groups both in the intervention and control group is comparably same, $28.18 \pm 0.82$ and $28.12 \pm 0.81$ (values \pm SEM) respectively. The BMI of the two groups and the clinical presentation as seen in table 1 are almost the same; which makes a good platform for comparing the outcome of the intervention.

The mean serum level of MDA and mean serum levels of antioxidants both enzymatic (GPx, SOD, CAT), non enzymatics (Vit A, Vit C, Vit E), Zinc and copper were not statistically different between the two groups at base line (pre-intervention) as seen in Table 2. However, 
previous studies have demonstrated higher levels of MDA and lower levels of the serum antioxidants in patents with PCOS compared with control. ${ }^{12,24-27}$ It is therefore likely that the parameters observed at baseline are comparatively to that observed in the infertile group in previous studies. ${ }^{26,27}$

However, after intervention with Vitacap $^{\mathbf{R}}$ which a capsule formulation is containing various non-enzymatic antioxidant and minerals as detailed in the methodology there was statistical significant difference in the mean serum levels of the oxidative stress marker (MDA) and antioxidants (both enzymatic and non-enzymatic) and minerals between the intervention and the control group which may be attributable to the antioxidant supplementation given to the intervention group. The mean serum level of MDA was lower in the intervention group compared to the control group $(\mathrm{p}=<0.007)$ and the mean serum antioxidants (GPx, SOD, CAT, Vit A, Vit C, Vit E) were all significantly higher than the control group (Table 3).

The result of the study points to the fact that antioxidant supplementation in the patients with PCOS may improve their chances of achieving pregnancy or correct the endocrinopathies associated with PCOS. The mean serum level of GPx, SOD and CAT, may have been improved in the intervention group perhaps because of the minerals contained in the supplement which includes copper sulphate, manganese sulphate and zinc sulphate being that the enzyme function of these antioxidants need these minerals as co enzymes. ${ }^{23,28}$ Antioxidant supplementation has also been shown to improve insulin sensitivity and other health threatening conditions in women with PCOS. ${ }^{12}$

The outcome of intervention with antioxidants and minerals in the study showed that $22 \%$ achieved pregnancy with $18 \%$ live birth in the intervention as against $2 \%$ respectively in the control group. This wide variation may be attributable to the supplements received by the intervention group. The significant pregnancy outcome relative to control in the current study is similar to the one obtained by Howard et al even though theirs was on unexplained infertility but differ from other randomised control trials which did not show significant difference in pregnancy rates. ${ }^{28,29-31}$ Most of the earlier studies used either minerals or vitamins as their supplement but in the current study a combination of minerals, vitamins and other antioxidants were used which may be responsible for the difference in outcome even though the index study was on PCOS patients. The antioxidant vitamins such as vitamins A, C, E and minerals such as zinc and copper are important in restoring and maintaining the oxidant and antioxidant balance in blood and tissue. ${ }^{31}$ the multivitamins and minerals ameliorates the oxidant changes probably through its free radical scavenging in the blood, serum and follicular fluids. ${ }^{31}$

\section{CONCLUSION}

The study demonstrates that antioxidants supplementation in patients with PCOS significantly affected the pregnancy rates. A larger multicentre study is suggested and a reassessment to revisit the conclusion of the Cochrane review that antioxidant supplementation had no significant role in female infertility.

\section{ACKNOWLEDGMENTS}

The authors would like to thank the Usmanu Danfodiyo University Sokoto for providing the research grant used in financing this expensive research. Authors extend their appreciation to all the research assistants, coordinators, nurses and records staffs of the Department of Obstetrics and Gynaecology for their role in the conduct of the trial. Authors thank Mallam Sani Bashir, Mallam Yazid Usman Bunza, Mr. Momoh A. Amanabo and other laboratory scientist that participated in the trial. Authors appreciate the other consultant and residents of the department for their role during the conduct of the research. Above all authors thank all the patients that participated in this trial.

\section{Funding: Grant research by Usmanu Danfodiyo University Sokoto \\ Conflict of interest: None declared \\ Ethical approval: The study was approved by the Institutional Ethics Committee}

\section{REFERENCES}

1. Joham AE, Teede HJ, Ronasinha S, Zanges S, Boyle J. Prevalence of infertility and use of fertility treatment in women with polycystic ovary syndrome; data from a large community based study. J Women Health. 2015;24(4):299-307.

2. Goodarzi MO, Dumestic DA, Chazenbalk G, Azziz R. Polycystic ovary syndrome; etiology, pathogenesis and diagnosis. Nat Rev Endocrinol. 2011;7:219-31.

3. Muni M, Luque-Mirez M, Insenser M, Ojede-Ojede M, Escobar-Morreds HF. Circulating markers of oxidative stress and polycystic ovary syndrome; a systemic review and meta-analysis. Hum Reproduction Update. 2013;19(3):268-88.

4. Victor VM, Rucha M, Banuls C, Alvarez A, DePablo C, Sachez-Ssrrano M, et al. Induction of oxidative stress and human leukocyte/endothelial cell interactions in polycystic ovary syndrome patients with insulin resistance. J Cli Endocrinol Metab. 2011;96(10):3115-22.

5. Al-Gugory KH, Fowler PA, Garrel C. The role of cellular reactive oxygen species, oxidative stress and antioxidants in pregnancy outcome. Int $\mathrm{J}$ Biochem. 2010;42:1634-50.

6. Burton GJ, Jaumiaux E. Oxidative stress. Best Pract Res Clin Obstet Gynaecol. 2010;25:287-99. 
7. Agarwal A, Saleh RA, Bedaiwy MA. Role of reactive oxygen species in the pathophysiology of human reproduction. Fertil Steril. 2003;79(4):82943.

8. Bellver J, Melo MA, Bosch E, Sewa V, Remotin J, Pellier A. Obesity and poor reproductive outcome; the potential role of the endometrium. Fertil Steril. 2007;88(2):446-51.

9. Miyamoto K, Sato EF, Kasahare E, Jikumaru M, Hiramoto K, Tabate $\mathrm{H}$, et al. Effect of oxidative stress during repeated ovulation on the structure and function of the ovary, oocyte and the mitochondria. Free Radical Biol Med. 2010;49(4):674-81.

10. Ternopusky MA. The mitochondrial cocktail; rationale for combined nutra centrical therapy in mitochondrial cytoplasm. Advanced Drug Delivery Rev. 2008;60(13):1561-671.

11. Agarwal A, Said TM, Bedaiwy MA, Banerjeas J, Alvarez JG. Oxidative stress in an assisted reproductive technique setting. Fertil Steril. 2006;86(3):503-12.

12. Al- Kateen MA, Ibrahim MA, Al- Jammal MHH, Shareef YS, Suleiman MA. Serum antioxidant vitamins changes in women with polycystic ovarian syndrome. J Bahrain Med Sci. 2010;22:68-71.

13. Rotterdam ESHRE/ASRM-sponsored PCOS consensus workshop group. Revised 2003. Consensus on diagnostic criteria and long-term health risk related to polycystic ovary syndrome (PCOS). Hum Reprod. 2004;19(1):41-7.

14. Paglia DE, Valentine WN. Studies on the quantitative and qualitative characterization of erythrocyte glutathione peroxidase. J Lab Clin Med. 1967;70(1):158-69.

15. Marklund SL. Expression of extracellular superoxide dismutase by human cell lines. Biochem J. 1980;266:213-9.

16. Niehans H, Samuel E. A comparative evaluation of TBARS method for the determination of MDA in biological materials J Rad Biol Med. 1968:15:35363.

17. Johansson B, Borg O. The interstitium of human arterial containing catalase. J Physiol. 1998;552(2):335-44.

18. Hashim SA, Schuttinger GR. Rapid determination of tocopherol in macro- and micro-quantities of plasma. Results obtained in various nutrition and metabolic studies. Ann J Nutr. 1966;19(2):132.

19. Natelson S. Determination of ascorbic acid using 2, 4-dinitrophenyl hydrazine; technique of clinical chemistry. $3^{\text {rd }}$ edition, Charles Thomas spring field USA; 1991:165-166.

20. Rutkowski M, Grzegorezyk K, Gendek E, Kedziora J. Laboratory conversional modification of Bassey method of vitamin A determination in blood plasma. J Physiol Pharm. 2006;57(2):221.
21. Fick KR, Mc Dowell LR, Miles PH, Wilkinson NS, Funk JD, Conrad JH. Method of mineral analysis for plants and animal tissues, $2^{\text {nd }}$ edition. Department of Animal Science, University of Florida, Gainesville; 1979:72-79.

22. Panti AA, Sununu YT. The profile of infertility in a teaching hospital in North West Nigeria. Sahel Med J. 2014;17(1):7-11.

23. Agarwal A, Allamenemi SS. Role of radicals in female reproduction. Reprod Biomed Online. 2004;9:339-47.

24. Deepika MLN, Malini S, Maruthi G, Ramchander V, Ranjith K, Latha KP, et al. Analysis of oxidative stress status through MN test and serum MDA levels in PCOS women. Pak J Biol Sci. 2014;17(4):574-7.

25. Zhang D, LUO WY, Liao H, Wang CF, Sun F. The effects of oxidative stress to PCOS. Scihuan Da Xua Bao Yi Xua Ban. 2008; 39(3):3333-40.

26. Panti AA, Ateeque UB, Rabiu UA, Saidu Y, Bilbis LS, Shehu CE, et al. Evaluation of oxidative stress, antioxidants, gonadotropins and prolactin in infertile women. Int J Gynaecol Obstet. 2015;131(5):E314607.

27. Majid KH, Hamza JM, Basima S, Al- Ghazah, Thamar MAH. Oxidative stress in primary infertility of women. Global J Med Res Sys. 2013;13(2):1-8.

28. Michiel C, Raes M, Toussant O, Ramade J. Importance of Se-gluthathione peroxidase, catalase, and cu/zn-sod for cell survival against oxidative stress, free radicals. Biol Med. 1994;17:235-48.

29. Howard JVC, Davies S, Hunnisset A. Red cell magnesium and glutathione peroxidase in infertile women: effects of oral supplementation with magnesium and selenium. Magnes Res. 1994;7(1):49-57.

30. Badawy A, EI Nashar BA, Totongy ELM. Clomiphene citrate plus $\mathrm{N}$ - acetyl cysteine versus clomiphene citrate for augmentation ovulation in the management of unexplained infertility; a randomized double-blind controlled trial. Fertil Steril. 2006;86(3):647-50.

31. Ozkaya MO, Mustafa N. Multivitamins and mineral supplementation modulates oxidative stress and antioxidant vitamins levels in serum and follicular fluid of women undergoing in vitro fertilization. Fertile Steril. 2010;94:2465-6.

Cite this article as: Panti AA, Shehu CE, Saidu Y, Tunau KA, Nwobodo EI, Jimoh A, et al. Oxidative stress and outcome of antioxidant supplementation in patients with polycystic ovarian syndrome (PCOS). Int J Reprod Contracept Obstet Gynecol 2018;7:1667-72. 